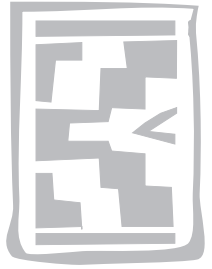

RESEARCH COMMUNICATION

\title{
Epidemiological survey on gastro-intestinal and blood-borne helminths of dogs in north-east Gabon
}

\author{
B. DAVOUST ${ }^{1 *}$, T. NORMAND ${ }^{2,5}$, O. BOURRY ${ }^{3}$, H. DANG ${ }^{2}$, E. LEROY ${ }^{3,4}$ \\ and G. BOURDOISEAU²
}

\begin{abstract}
DAVOUST, B., NORMAND, T., BOURRY, O., DANG, H., LEROY, E. \& BOURDOISEAU, G. 2008. Epidemiological survey on gastrointestinal and blood-borne helminths of dogs in north-east Gabon. Onderstepoort Journal of Veterinary Research, 75:359-364

A survey of helminth parasites was carried out on 198 dogs living in almost complete liberty in villages in the northeast of Gabon. Faeces and blood samples were collected and analysed. Dirofilaria immitis antigen was detected in $13.6 \%$ of dogs using the SNAP 3Dx@ test, a commercially available enzyme-linked immunosorbent assay (ELISA). Faecal examination revealed that $91.4 \%$ of dogs were infected by intestinal helminths. Ascarids were found in $58.5 \%$ of the samples. Trichuris vulpis was observed in $49.5 \%$ of cases, and Uncinaria spp. and Ancylostoma spp. in $34.8 \%$, Spirocerca lupi in $25.3 \%$ and Capillaria spp. in $10.6 \%$. Cestode embryophores were found in $8.6 \%$ of the samples.
\end{abstract}

Keywords: Dirofilariosis, dog, faecal examination, Gabon, helminths, intestinal parasite infection, zoonosis

\section{INTRODUCTION}

In Equatorial Africa, helminths, particularly nematodes and cestodes, regularly infect dogs as shown in prevalence studies conducted in Nigeria (Ugochukwu \& Ejimadu 1985), the Congo (Pangui \& Belot 1986) and the Democratic Republic of the Congo (Chartier \& Chartier 1990). In Gabon, a country located on the Equator, under the Gulf of Guinea,

* Author to whom correspondence is to be directed

1 Direction régionale du service de santé des armées de Toulon, BP 80, 83800 Toulon Armées, France

E-mail: bernard.davoust@mageos.com

2 Laboratoire de parasitologie, Ecole nationale vétérinaire de Lyon BP 83, 69280 Marcy l'Etoile, France

3 Centre international de recherches médicales, BP 769, Franceville, Gabon

4 Institut de recherche pour le développement, UR034, Paris, France

5 Service vétérinaire, Centre national d'instruction cynophile de la Gendarmerie, 46500 Gramat, France

Accepted for publication 14 August 2008-Editor a survey carried out in Libreville showed that $64 \%$ $(43 / 67)$ of dogs carried intestinal helminths and that $50 \%(24 / 48)$ were infected by Dirofilaria immitis (Beugnet \& Edderai 1998).

The aim of our study was to establish the prevalence of dirofilariosis and intestinal helminthosis in dogs, in a rural region of Gabon, situated $500 \mathrm{~km}$ to the east of Libreville. The survey comprised the collection of blood and faecal samples in 2003 followed by their analysis in the Parasitology Laboratory at the Ecole nationale vétérinaire (National School of Veterinary Medicine) in Lyon, France.

\section{MATERIALS AND METHODS}

Our study focused on a population of semi-stray dogs living in 16 areas of Ogooué-Ivindo, a northeastern region of Gabon. The climate in this zone is typically equatorial with a dry season between midJune and mid-August. The cumulative annual rainfall is approximately $1700 \mathrm{~mm}$. 
The survey was carried out on 198 mongrel dogs between 3 months and 14 years of age (average age: 2 years 7 months).

The screening for dirofilariosis was carried out by testing serum samples using the SNAP 3Dx® test (IDEXX Laboratories Inc. USA). The SNAP 3Dx test is a rapid in-clinic assay that simultaneously detects heartworm antigen and antibodies to Borrelia burgdorferi and Ehrlichia canis in whole blood, serum or plasma. Results of the heartworm antigen assay are reported here, while the seroprevalence of $B$. burgdorferi and $E$. canis was published elsewhere (Davoust, Bourry, Gomez, Lafay, Casali, Leroy \& Parzy 2006).

Faecal samples were immersed in $10 \%$ formaldehyde on collection and poured into labelled $10 \mathrm{ml}$ tubes. Intestinal parasites were identified using a faecal flotation enrichment technique. In this procedure, $5 \mathrm{~g}$ of faeces were collected from each tube, suspended in $20 \mathrm{ml}$ of potassium iodomercurate and filtered through a sieve. The filtrate was poured into a $5 \mathrm{ml}$ test tube, filled to the maximum, covered with a cover slip and centrifuged at $2500 \mathrm{rpm}$ for 5 min. The cover slip was deposited on a slide labelled with the name of the sample, and examined under a compound microscope. Each type of parasite egg or larva was counted using 40x magnification, and the eggs and larvae were identified using magnifications of $100 x$ and $400 x$.

\section{RESULTS}

The test for circulating $D$. immitis antigen was positive in 27 of the 198 sera tested (13.6\%). Intestinal parasites were detected in 181 of $198(91.4 \%)$ of the stool samples analysed (Fig. 1). Toxocara canis was detected in $58.5 \%(116 / 198)$, Uncinaria and Ancylostoma spp. in $34.8 \%$ (69/118), Trichuris vulpis in $49.5 \%$ (98/198) and Capillaria spp. in 10.6\% $(21 / 198)$ of the samples. Spirocerca lupi eggs were present in $25.3 \%(50 / 198)$ of the samples. Cestode embryophores were present in $8.6 \%$ of the samples (17/198); but the species could not be identified due to the absence of gravid segments.

More than one parasite was found in the faeces of $61.6 \%$ of the dogs containing intestinal parasites (122 out of 181 infected dogs). Sixty dogs were infected by two species. The most common combination involved 29 dogs infected with Toxocara canis and Trichuris vulpis. Sixty-two (34\%) of the dogs were infected by at least three species, 22 of these harboured Toxocara canis, Ancylostoma spp. and Trichuris vulpis.
A more detailed study of Ancyclostoma spp. (hookworm) infection in the dogs showed that $73 \%$ of the 69 infected dogs were less than 4 years of age. It was noted that $98 \%$ of these dogs strayed freely through the villages and $76 \%$ frequented the forest where they could come into indirect contact with the wild fauna. Similarly, of the 117 dogs with ascarid infection, $64 \%$ were either puppies or young adults, less than 4 years old. The dogs that had tapeworm embryophores in their stools were also young: $59 \%$ of them were under 4 years of age. Analysis of the data using the Chi-square test showed that dogs under the age of 4 years were more prone to parasitic infection than those aged 4 years and above $(P<0.001)$.

\section{DISCUSSION}

Previous studies have shown that the SNAP 3Dx® screening test for dirofilariosis had $100 \%$ specificity and $98.1 \%$ sensitivity (O'Connor, Esty, Machenry, Hanscom, Bartol \& Lawton 2002). This test is extremely easy to perform. The prevalence of dirofilariosis in the survey area (13.6\%) was moderate compared with the $50 \%$ previously reported in Libreville (Beugnet \& Edderai 1998). Infection with D. immitis frequently occurs in tropical countries where its mosquito vectors are present throughout the year.

Use of the faecal flotation enrichment method is justified because this technique has good sensitivity. Our faecal survey, however, does not necessarily reflect the real level of infection. For instance, the excretion of cestode eggs is erratic, and the study was conducted in dogs that had owners but were nevertheless allowed to roam freely in the villages. Most of the dogs had never received veterinary care or anthelminthic treatment. The typically equatorial climate of Gabon, characterised by constant high temperatures, an annual average of $26^{\circ} \mathrm{C}$, perpetual high humidity between $80 \%$ and $96 \%$ and an abundant rainfall, promotes the maturation and survival of the infective stages, namely eggs or helminth larvae.

Soil type and texture have a direct influence on the outdoor survival of eggs and larvae. Moist, sandy and shaded soils are far more conducive to parasite survival than concrete areas that are regularly cleaned. The dogs in the Gabon villages of the Ogooué-lvindo region are, therefore, in an environment that is particularly favourable for the parasites.

The more detailed hookworm study, as confirmed in other studies focusing on these parasites, showed 


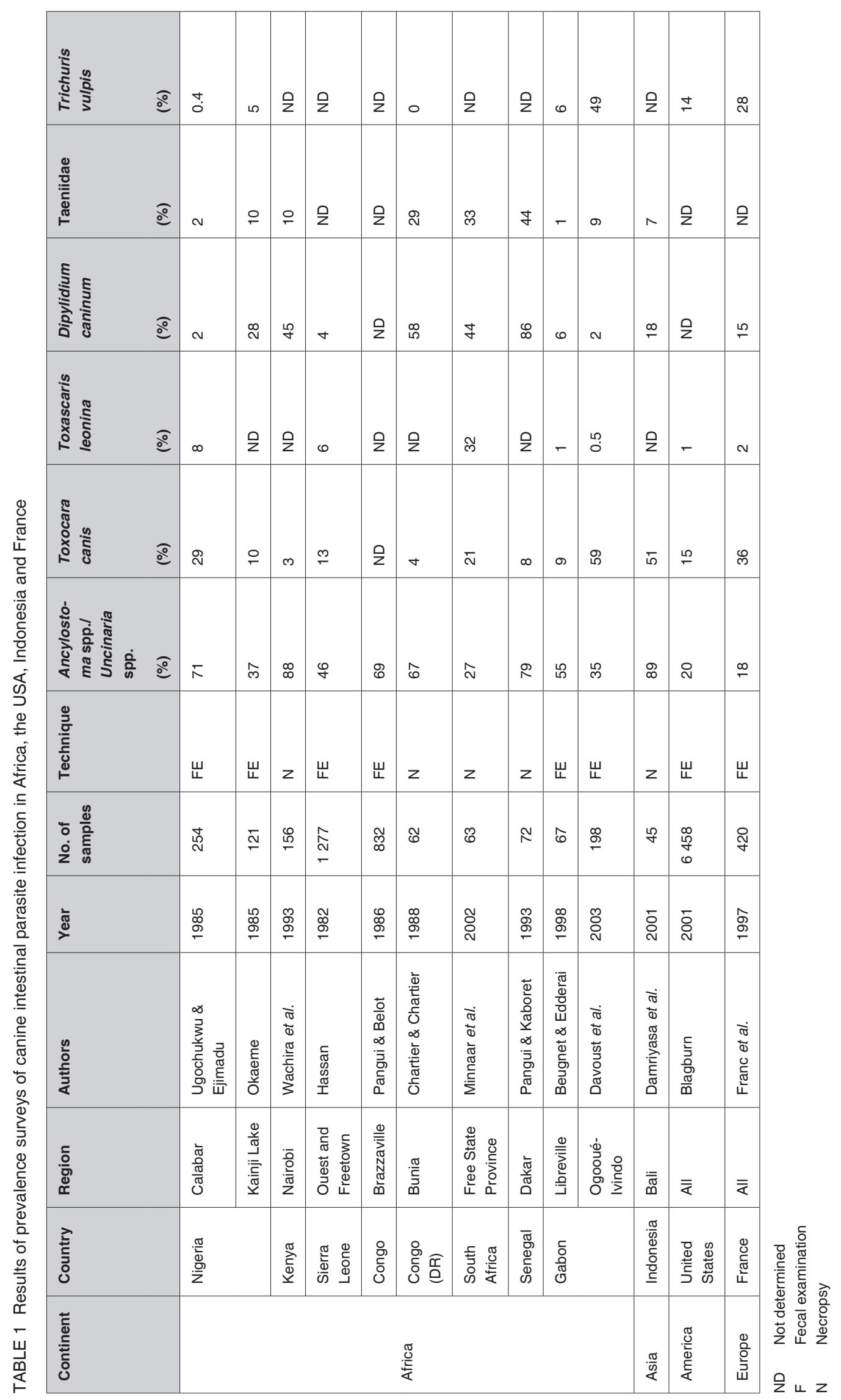




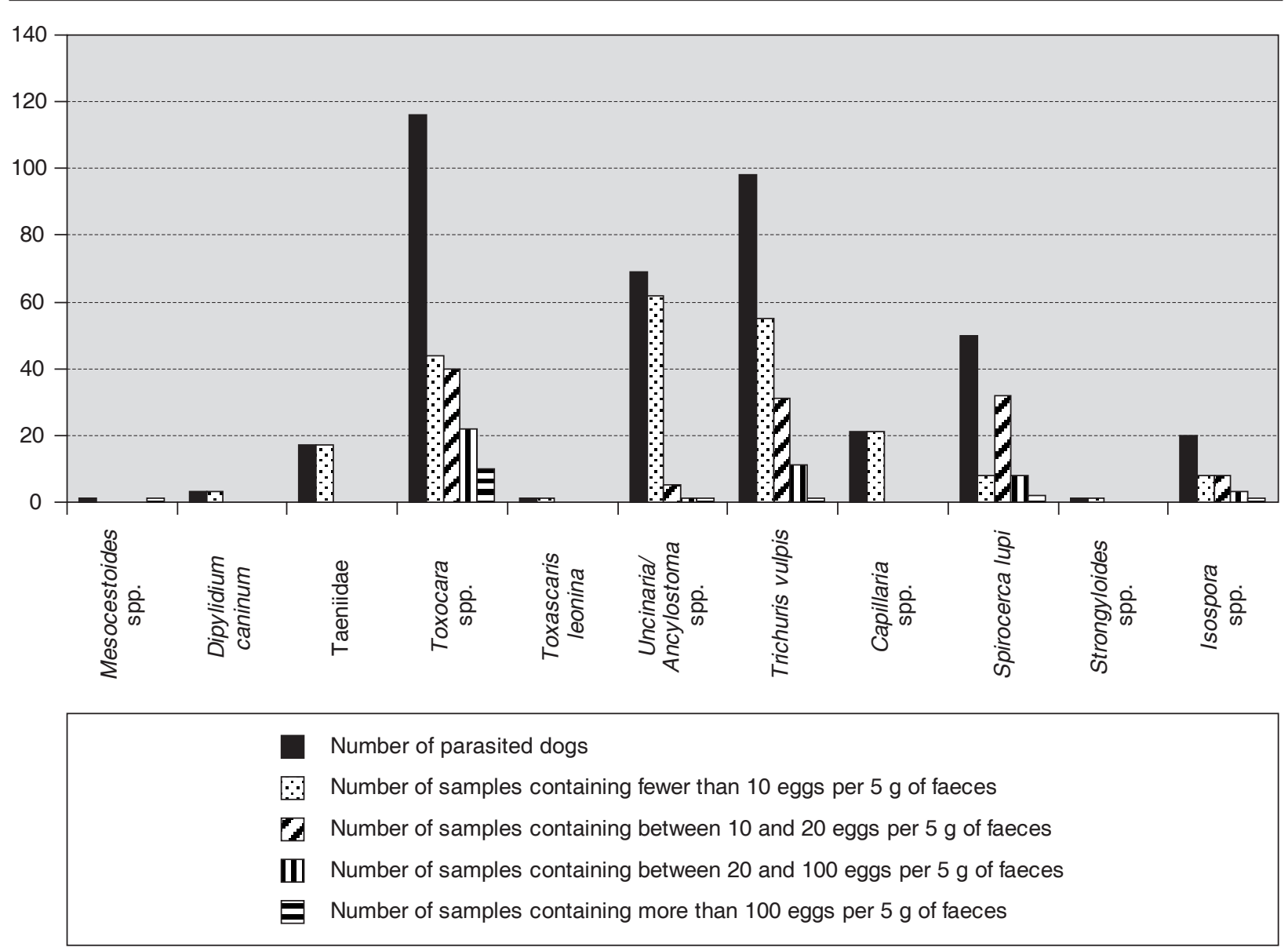

FIG. 1 Results of coproscopies conducted in 198 dogs

that the animals affected were mainly puppies and young dogs, as $73 \%$ of the 69 dogs infected by hookworm were under 4 years of age. This result is comparable with the $76 \%$ found in the study conducted in Libreville by Beugnet \& Edderai (1998). The high level of infection in this age group can be explained by a poorly developed immunity in the young dogs, and the thinness of their skin, which is conducive for penetration by hookworm larvae. This is not to exlude other routes such as via milk or faeces. Moreover, in our study, $98 \%$ of the 69 dogs infected by hookworm lived outdoors and were sources of parasites for non-infected dogs and $76 \%$ of them had access to the forest which could have been contaminated by faeces of other carnivores. In the study by Beugnet \& Edderai (1998), it was extrapolated that there was an $85 \%$ prevalence of these parasites in untreated stray dogs. In the Congo, the prevalence of hookworm reached $68.6 \%$ in a population of 832 dogs (Pangui \& Belot 1986). In Dakar (Senegal), prevalence rates of $79.7 \%$ (57/72) for Ancylostoma braziliense and $17.4 \%(12 / 72)$ for A. caninum were observed at autopsy (Pangui \&
Kaboret 1993). In our study, Ancylostoma spp. eggs were found only $35 \%$ of the dogs examined.

The two species of ascarids, Toxocara canis and Toxascaris leonina were regularly encountered in our survey. In the study conducted by Beugnet \& Edderai (1998), the prevalence of ascarids was $10 \%$ in a canine population $(n=67)$ under veterinary surveillance in Libreville, but the prevalence was over $59 \%$ in dogs not receiving any veterinary care (Beugnet \& Edderai 1998).

Table 1 shows the results of faecal surveys carried out on dogs in Africa, the USA, Indonesia and France. In the Ogooué-Iwindo region of Gabon, the prevalence of ascarid infection was higher than in other African countries and in Bali (Indonesia) (Damriyasa, Surathma, Dwinata, Apsari, Schares, Nöckler, Schein \& Bauer 2001). This difference is, perhaps, related to the test populations, some of which benefited from anthelmintic treatment. It is also noteworthy that, regardless of the region investigated, the prevalence of Toxocara canis was always far higher than that of Toxascaris leonina. In our study, 
the prevalence of Toxascaris leonina was $0.5 \%$, compared to $8 \%$ and $32 \%$ in Nigeria and South Africa, respectively (Ugochukwu \& Ejimadu 1985; Minnaar, Krecek \& Fourie 2002).

The prevalence of trichurosis in Gabon (49 \%) was higher than that reported by other authors in Africa (Table 1). In Nigeria, the prevalence rate was only $5.4 \%$ (Okaeme 1985). It therefore seems that climatic and sanitary conditions are not responsible for the prevalence observed. Trichuris eggs, like those of Toxocara and Toxascaris, are highly resistant to harsh environmental conditions and can, perhaps because of their thick shell, survive well in mud and anaerobic conditions.

The prevalence rate $(25 \%)$ for S. lupi that we observed was high, bearing in mind that faecal excretion of their eggs is intermittent. Lesions, such as presence of oesophageal nodules, observed in necropsy allow a better evaluation of the rate of infection.

Three gravid proglottids of Dipylidium caninum were found in three separate samples in our study and $8.6 \%$ of the dogs were carriers of taeniid embryophores. Levels of $86 \%$ and $58 \%$ were recorded in Dakar (Sénégal) and Bunia (Democratic Republic of Congo), respectively (Pangui \& Kaboret 1993; Chartier \& Chartier 1990). The low prevalence is related to the low numbers of livestock in the Gabon village studies. In Senegal, $44.9 \%$ of dogs $(n=72)$ were infected with Taenia hydatigena (Pangui \& Kaboret 1993).

Several intestinal parasites of dogs in Gabon dogs are capable of infecting man: Ancylostoma caninum, Toxocara canis and possibly Echinococcus granulosus. The transmission of these parasites is often due to poor hygiene (Petithory, Beddok \& Quedoc 1994).

Our study by faecal examination did not enable us to evaluate the parasite infection-related zoonotic risk to dogs posed by echinococci (E. granulosus or Echinococcus multilocularis). Since the samples contained taeniid eggs, additional studies using molecular biology techniques are planned using the frozen faeces that were collected from the same 17 dogs.

The incidence of parasitic infection in the canine population, confirms that intestinal helminthosis of carnivores is an important health problem. In the light of this, sanitation and improved food and water as well as environmental conditions could reduce the level of human and canine infection in villages of
Equatorial Africa. In addition, dogs can also occasionally transmit zoonotic parasites to man, cutaneous and visceral larval migrans being two of the more important ones. Whilst it would seem correct to regularly deworm dogs, this is practically impossible in view of the fact that the villagers have not the means to treat their own parasitic infestations.

\section{ACKNOWLEDGMENTS}

The authors gratefully acknowledge the excellent technical assistance of Loïs Allela and André Delicat and the Association pour la recherche en infectiologie, IDEXX Laboratories, Inc. and the Vétoquinol Companies for their material support. The Centre international de recherches médicales de Franceville is supported by the Government of Gabon, TotalFina-Elf Gabon and the French Ministry for Foreign Affairs. This work was also supported by a Fonds de solidarité prioritaire grant from the French Ministry for Foreign Affairs (FSP No. 2002005700).

\section{REFERENCES}

BEUGNET, F. \& EDDERAI, D., 1998. Enquête sur les helminthes parasites digestifs et sanguins chez les chiens à Libreville, Gabon. Revue de Médecine Vétérinaire, 149:327-330.

BLAGBuRN, B.L. 2001. Prevalence of canine and feline parasites in the United States. Supplement to the Compendium on Continuing Education for the Practicing Veterinarian, 23: 5-10.

CHARTIER, C. \& CHARTIER, F. 1990. Les helminthes du chien domestique dans le Nord-Est du Zaïre. Revue de Médecine Vétérinaire, 141:771-775.

DAMRIYASA, I.M., SURATHMA, N.A., DWINATA, I.M., APSARI, I.A.P., SCHARES, G., NÖCKLER, K., SCHEIN, E. \& BAUER, C. 2001. Parasite infections in semi-domesticated dogs in Bali, Indonesia. 18th Conference of the World Association for the Advancement of Veterinary Parasitology, Stresa, Italy, 26-31 August 2001.

DAVOUST, B., BOURRY, O., GOMEZ, J., LAFAY, L., CASALI, F., LEROY, E. \& PARZY, D. 2006. Surveys on seroprevalence of canine monocytic ehrlichiosis among dogs living in the Ivory Coast and Gabon and evaluation of a quick commercial test kit Dot-ELISA. Annals of the New York Academy of Sciences, 1078:464-469

FRANC, M., CADIERGUES, M.C., MARCHAND, A., BOURDOISEAU, G. \& BUSSIERAS, J. 1997. Le parasitisme intestinal des carnivores domestiques: bilan d'une enquête conduite dans les quatre Ecoles Vétérinaires Françaises. Revue de Médecine Vétérinaire, 148:247-250.

HASSAN, I.C. 1982. Gastrointestinal helminth parasites of dogs in the Western Area Freetown (Sierra Leone). Beitrage zur Tropischen Landwirtschaft und Veterinärmedizin, 20:401407.

MINNAAR, W.N., KRECEK, R.C. \& FOURIE, L.J. 2002. Helminths in dogs from a peri-urban resource-limited community in Free 
State Province, South Africa. Veterinary Parasitology, 107: 343-349.

O'CONNOR, T.P., ESTY, K.J., MACHENRY, P., HANSCOM, J.L., BARTOL, B.A. \& LAWTON, T. 2002. Performance evaluation of Ehrlichia canis and Borrelia burgdorferi peptides in a new Dirofilaria immitis combination assay, in Advances in Heartworm Disease: Symposium '01, edited by R.L. Seward. Batavia: American Heartworm Society: 77-84.

OKAEME, A.N. 1985. Canine and human gastrointestinal helminthiasis of the Kainji Lake area, Nigeria. International Journal of Zoonoses, 12:241-246.

PANGUI, L. \& BELOT, J. 1986. L'ankylostomose canine à Brazzaville (République Populaire du Congo). Revue de Médecine Vétérinaire, 137:181-185.
PANGUI, L.J. \& KABORET, Y. 1993. Les helminthes du chien à Dakar, Sénégal. Revue de Médecine Vétérinaire, 144:791794.

PETITHORY, J.C., BEDDOK, A. \& QUEDOC, M. 1994. Zoonoses d'origine ascaridienne: les syndromes de larva migrans viscérales. Bulletin de l'Académie Nationale de Médecine, 178: 635-647.

UGOCHUKWU, E.I. \& EJIMADU, K.N. 1985. Studies of the prevalence of gastro-intestinal helminths of dogs in Calabar, Nigeria. International Journal of Zoonoses, 12:214-218.

WACHIRA, T.M., SATTRAN, M., ZEYHLE, E. \& NJENGA, M.K. 1993. Intestinal helminths of public health importance in dogs in Nairobi. East African Medecine Journal, 70:617-619. 